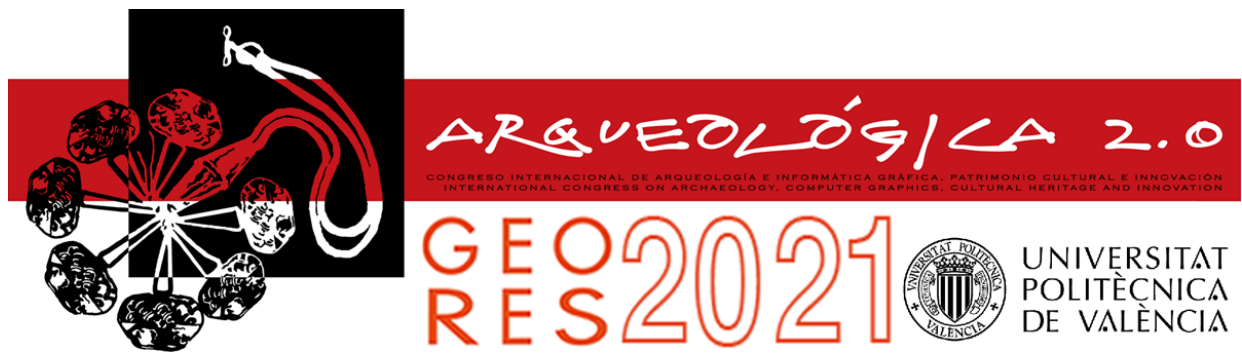

Proceedings of the joint international event $9^{\text {th }}$ ARQUEOLÓGICA

$2.0 \& 3^{\text {rd }}$ GEORES

Valencia (Spain).

26-28 April 2021

\title{
YEDI KULE - MONUMENT ROAD RACE: THE CONSTRUCTION OF THE 3D MAPPING ANIMATION OF THE OLD CITY OF THESSALONIKI, GREECE
}

\author{
Efthymios-Spyridon Georgiou ${ }^{\mathrm{a}}$, Nikos Lambrinos ${ }^{\mathrm{b},{ }^{*}}$ \\ a Master Integrated School Spatial Planning and Development, Department Engineering, Aristotle University of Thessaloniki, \\ Thessaloniki GR-54124, Greece. efthimios_georgiou@yahoo.gr \\ ${ }^{b}$ Department of Primary Education, School of Education, Aristotle University of Thessaloniki, Thessaloniki GR-54124, Greece. \\ labrinos@eled.auth.gr
}

\begin{abstract}
:
This project refers to the construction of a 3D map of Thessaloniki's historical route. The Yedi Kule Conquest - Monument Road Race took place in the old city of Thessaloniki, which was built during the Byzantine and Ottoman period. The purpose of this project is to make a digital recording of the castles, the monuments, the old churches, the traditional buildings, and the squares that the contestant encounters during the route so he/she can be aware of the characteristic points he/she will meet during the race. The methodology of the project is based on the implementation of online software Google Earth Studio and Adobe Premiere Pro which were used for the digitization, rendering, and building process of the animation. With this methodology, the authors achieved the documentation of land use and the architectural landscape. The animation is a credible graphic index of the historical background of Thessaloniki. The Yedi Kule area constitutes a cultural mosaic made during the Ancient Greek/Roman, Byzantine, and Ottoman Empire historic periods. The responsibility of the governmental politics and of every citizen of Thessaloniki is to promote and preserve the historic background of the city. The final product offers a good opportunity for the digital storage of Thessaloniki's old city. The animation creates an interactive environment that portrays the current image of the transition from the old to a modern city.
\end{abstract}

Keywords: 3D mapping, animation, cultural landscape, Thessaloniki, Greece

\section{One City Many Cultures}

Thessaloniki city was founded in 315 B.C. by Kassandros, General of Alexander the Great. Its main history starts in the Hellenistic period (321 - 31 B.C.) and reaches until today, without losing its urban-metropolitan and multicultural character. It presents over 2,000 years of continuous uninterrupted urban life. Its history is constantly marked by intense discontinuities and ruptures. (Mazower, 2006).

Due to its geographical location, has a very important role in Greek and Balkan history, was a crossroads of people and cultures, but also a major commercial centre. For this reason, various conquerors claimed it and tried to occupy it.

Thessaloniki, the "metropolis of Macedonia" according to Strabo, the "first after the first" or the "ruling" city of Byzantine sources, took her name after the wife of Kassandros. Thessaloniki was the daughter of Philip II and Nikisipolis from Ferres, Thessaly (Central Greece). The new city formed after the clustering of 26 settlements located in the area. (Strabon, 1992).
Byzantine Thessaloniki managed to maintain its vitality and dynamism, despite the successive and repeated sieges (and sometimes outbursts) it experienced from various invaders (Goths, Avars, Slavs, Saracens, Bulgarians, Arabs, Catalans, Dutch, Catalans).

According to Mazower (2006), Thessaloniki has already started to become a melting pot of peoples, traditions, and cultures since Byzantine times.

In Roman times, Thessaloniki became the capital of an extensive administrative district, the Province of Macedonia (Provincia Macedonia). It was the most important city along the Egnatia Highway, the famous military road that started from Durres and ended in Evros (today Greek Turkish borders), connecting the west with the Asia Minor possessions of the Roman Empire. On March 29, 1430, Thessaloniki was finally conquered by the Ottomans and a new chapter opened in its history. Thessaloniki during the Ottoman occupation was a city that could be characterized as multinational. (Vakalopoulos, 1983).

During the Ottoman period and mainly from the $15^{\text {th }}$ century onwards, Thessaloniki began to host very large 
numbers of refugees, who settled there. The arrival of approximately 20000 expelled Jews from Spain in 1492 who in fact will baptize Thessaloniki "Mother of Israel", will be one of the most decisive factors in shaping its multicultural profile and will pave the way for customs. (Benbassa, Rodrigue, \& Jewry, 2000).

Mazower (2006) characteristically states that in the mid$16^{\text {th }}$ century the merchants of the Egyptian market, mainly a food market, spoke eleven languages: Greek, Turkish, Italian, French, Spanish, Vlach, Russian, Latin, Arabic, Albanian and Bulgarian. Nowadays the same place is called "Ladadika" and served as a food market until 1990 and now is a recreational area full of tavernas and bars.

Especially after the fire of 1620, the spatial rearrangements that took place were maintained until 1850. Specifically, the neighbourhoods were a nationreligiously separated: Muslims lived in Ano Poli, Orthodox lived in various areas along the Egnatia Road, around the Valtada Monastery, Vardari, and the Diocese, Jews lived near the sea below the Egnatia Road, while the area around the church of Agios Minas - due to the establishment of consulates and European traders - was named "Frangomahalas" (Gerolympou-Karadimos, 1995).

The establishment of the French consulate in Thessaloniki in 1685, underlines the intense trade relations with the Franks, while indicative of the prosperity of the city is the testimonies of travellers of the time. A typical example is the testimony of the priest and writings of Jozefdela Portoopoios in 1737 stating that Thessaloniki numbered 48 mosques, 30 Greek churches, and 36 Jewish synagogues (Gregoriou, \& Hekimoglou, 2008).

According to historical documents, the multicultural element of Thessaloniki continued to be dominant even after the liberation of the city from the Ottomans.

In addition, according to historical sources, in the 1915 parliamentary elections $14204(37 \%)$ Israelis, 13353 (35\%) Greek Orthodox, 8900 (23.11\%) Muslims, 700 $(1.8 \%)$ Armenians and $969(2.5 \%)$ of other ethnicities were registered to vote (Anastasiadis, 2011).

Thessaloniki joined the Greek state with the Treaty of Bucharest of August 10, 1913. Despite guarantees of economic and social protection, a large number of Jews, 800 merchants and capitalists, and about 500 craftsmen left Thessaloniki (Pierron, 2004).

An important event in the modern history of Thessaloniki was the fire that broke out in August 1917 starting from a house in the Muslim quarter on the outskirts of Ano Poli, which spread rapidly due to strong wind, wooden structures, paving, and lack of proper infrastructure for to deal with it, at a time when General Saray had refused to give up the barracks' reserves to water (Machaira, 2002). The fire was devastating for most of the historic city centre: 3.900 shops and 14,200 houses were burned, while 73.448 residents were left homeless, 52.000 of whom were Jews. (Machaira, 2002).

The arrival of the refugees was the starting point of the spatial and social transformation of Thessaloniki. During the period 1922-1928, the population of the urban area of Thessaloniki (Fig. 1) increased by $37.50 \%$ (Giannakou, 2015).

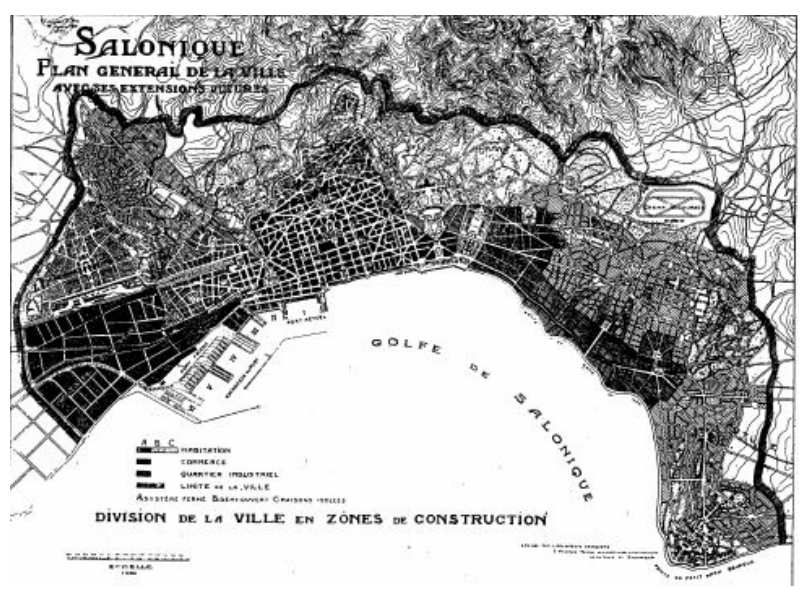

Figure 1: The plan for Thessaloniki by E. Hébrard, 1918 (from Hastaoglou-Martinidis, 1997).

At the dawn of the $21^{\text {st }}$ century, the Macedonian capital, responding and adapting to situations and conditions that are constantly differentiating, is moving towards the future, but its past is evident thanks to the number of monuments that are scattered within the current urban fabric: Hellenistic and Roman antiquities, Byzantine churches with mosaics and frescoes, imposing architectures such as walls, towers, and fortresses, Ottoman mosques, and baths, stand out among multistory apartment buildings, represent the timeless.

The historical site of Ano Poli transformed during the previous centuries. Despite this urban phenomenon, the area keeps the traditional architecture and the memories of the mosaic of urbanism from the ancient/roman, Byzantine, Ottoman period. Nowadays, Ano Poli is a tourist attraction and a place with many elements of the historical background of Thessaloniki. In fact, the modernization of the city shaped the "travel in the history", when the inhabitants, tourists and other people visited Ano Poli.

\subsection{Historical background of the race}

A sports and cultural celebration takes place every year in the Upper City of Thessaloniki. The $5.6 \mathrm{~km}$ road race. Yedi Kule Conquest is organized by SFENDAMOS with co-organizer the Thessaloniki Tourism Organization. The route of the struggle has the peculiarity of highlighting eight monuments of Thessaloniki and specifically: Eptapyrgio, Vlatada Monastery, Saint David, Byzantine Baths, Agios Nikolaos ton Orfanon, Islahane, Pasha Gardens, Tower of Chain.

This sporting cultural route gives life and content to the monuments of the city and turns them into institutions of sustainable development and ambassadors of the history of nature and culture (Diazoma, 2018). The goal of the organizers, in this historical retrospect of centuries, crossing the historical alleys, is the promotion of Ano Poli, with its historical monuments and rich cultural heritage as a tourist destination.

The route starts from the acropolis of Thessaloniki, the Eptapyrgio (Yedi Kule) (Fig. 2), which is identical to the history of the city. It is a very important historical monument, which consists of a polygonal fortress on the northeastern side of the Acropolis and owes its name to its seven rectangular towers. Together with the central 
tower of the entrance, they create a P-shape. It has a total of ten fortification towers while its original layout is placed in the post-Byzantine years. A similar fortress was built in Istanbul at the same time. Following our route, we meet the patriarchal Monastery of Vlatada, also known as Tsaous Monastery, which is one of the most important Byzantine monuments of the city.

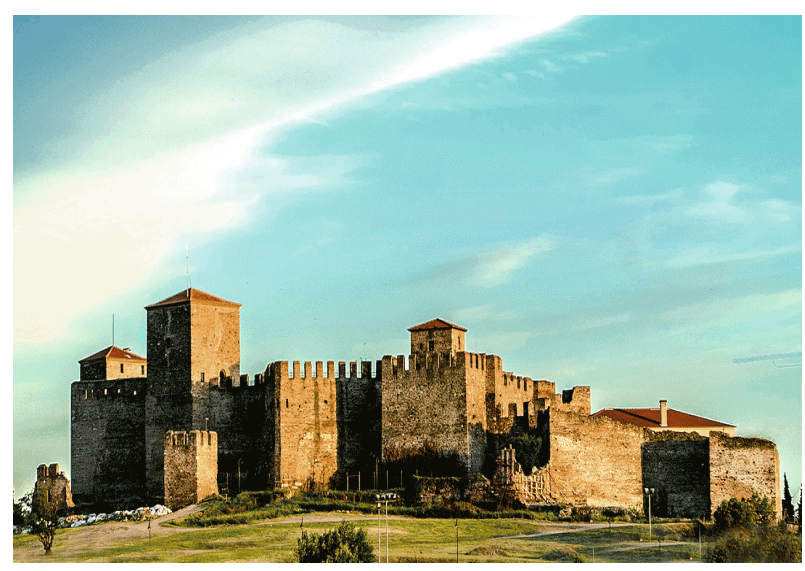

Figure 2: Heptapyrgion- Yedi-Kule: (Thessaloniki tourism Organization, 2020).

On our trip we meet the Temple of Saint David, it is an early Christian monument of great archaeological value, both for its antiquity and the precursor architectural style of the temple (cruciform with a dome), as well as for its interior decoration. (Unesco World Heritage Site, 2020)

The Byzantine baths the Byzantine Bath of Ano Poli is the only Byzantine Bath that survives from the mid-Byzantine or late Byzantine period in Greece and one of the few surviving secular buildings of that time. Its value as a monument is great and its urban position holds important.

Of unparalleled value and beauty is the Church of Agios Nikolaos of Orfanos is an old Byzantine monastery of Thessaloniki and a World Heritage Site, built in the early $14^{\text {th }}$ century. It is located in the northeast corner of Ano Poli, within the walls, between Herodotou and Apostolou Pavlou streets.

In the middle of the eastern walls of the city, near the New Golden Gate, dominates the School of Arts and Professions Hamidie, or Islahane of Thessaloniki, or otherwise Polytechnic Midat Pasha. It is the first complex of an orphanage - technical school in the city during the last period of Ottoman rule in Thessaloniki, an illustrative example of the reforms undertaken by the Ottoman Empire during the Tanzimat period (1839-1876), but also of the wider modernizing educational trends of the time.

A sample of Fantastic Architecture from the era of eclecticism, we enjoy in the Gardens of Pasha. It is a fenced park that occupies an area of about 1000 sqm. On the northeast side of the walls of Ano Poli is one of the most important historical, morphological and architectural monuments of Thessaloniki, it is the Tower of Chain or the Belted Tower.

And this is probably due to the stone decorative strip, which surrounds the trunk of the Tower like a chain. It was built to strengthen the fortification of Thessaloniki. The runner of Yedi Kule Conquest followed the material and intangible traces of Ano Poli of Thessaloniki and breathed the air of 2,500 years of history and culture through a modern integrated cultural-sports route.

\subsection{The Coronavirus pandemic crisis as a factor of delay}

The rapidly spreading of Coronavirus caused the Greek government to take measures against it. The most serious measure was the lockdown from March 2020 until May 2020. During that period the University was closed and everything was in online progress. That was also the case for this research, which faced a big delay due to unpredictable circumstances.

There were online meetings and the data processing took more time than it was scheduled. Even transportations were suspended and the research team could not visit the places where the race is going to take place. Nevertheless, people have the "privilege" to live in the first global crisis of the digital world and it looks like they have more tools to overcome the crisis than our ancestors had when facing health crisis or other crisis in their day. Talking about "tools", our communities use social media which can inform (either in a positive or negative way) people. Health crisis gave motive to a unique and global research, part of which concluded that civilians started to support public authorities more than before (Merkley et al, 2020; Harell, 2020; Bol, Giani, Blais, \& Loweven, 2020). Research showed that lockdowns had a positive effect on support for democracy (Bol, Giani, Blais, \& Loweven, 2020). The same think (political support) has been observed after a major crisis such as a terrorist attack (Hetherington, \& Nelson, 2003; Balcells \& TorratsEspinosa, 2018).

In our case, what we expect is that the restrictions imposed by the health crisis and the government, which include among others, social distancing and less audience (people attending the race) will have an impact on the monitoring of the race (under the framework of the, so-called, political support). People will try to follow the instructions for attending the race virtually. In order to overcome the problem, we decided to build the trace of the race onto a $3 \mathrm{D}$ image of the area.

\section{Introduction in Google Earth Studio}

Google Earth Studio is one of the most popular Google Earth and virtual globe applications that offer most of the planet free access to high-resolution imagery. According to scientific indexes, Google Earth (GE) has been downloaded more than 1 billion times on desktop and mobile clients since the introduction of the Google Earth software in 2005 (Guo et al., 2020).

Google Earth Studio is a browser-based animation platform for Google Earth 3D and satellite imagery that is unique and distinct. From large-scale geological features to individual city buildings, Google Earth has a vast store of $2 \mathrm{D}$ and $3 \mathrm{D}$ Earth data. The best way to utilize this imagery for still and animated material is with Google Earth Studio.

We based Google Earth Studio on industry-standard animation software, so it can be picked up by motion professionals and started to animate immediately. Helpful tools like Quick Starts make it possible, extremely quickly, for anyone to create beautiful animations. This documentation includes a detailed overview of the 
features of Earth Studio, as well as tips on how to use the product to produce the best-looking results quickly (Google Earth Studio, 2020).

Google Earth (GE) is a software developed by Google for the virtual world. On a three-dimensional model of the earth, it arranges satellite images, aerial photographs, and GIS.

\section{Methodology}

\subsection{Main steps}

The working group used Google Earth Studio in order to proceed with the project. Initially, a license was requested by the company, so the online software could be used for scientific purposes and more specifically, for the construction of the three-dimensional map. The design of the project followed these steps:

- Draw the race route in the GIS GRASS software.

- Connect the digitized race route to Google Earth Studio software.

- Delimitation of the study area with appropriate location of the camera station.

- Draw the map with successive overlaid images.

- Place labels in every point of historical and cultural interest.

- Render of the successive images.

The result is a three-dimensional video map, which highlights the architectural and urban planning ensembles of the study area. The importance of the sporting event, which is organized under the auspices of the municipality of Thessaloniki, contributes to the promotion of the history of the study area.

\subsection{Camera Targeting}

The camera is located to a steady place and the view angle changes respectively in accordance to/and following the route of the race from the start to the middle and up to the end of it.

A major challenge the working group had to face was the relationship that occurs between the point where the camera was located and the points of the route because the distance between each of these points and the camera was constantly changing, Eq. 1 :

$X+d_{1} \neq X+d_{2}$

For each $d(1,2,3 \ldots \mathrm{n})$

For each $P(1,2.3 \ldots . n), P \in N$

where

$$
\begin{aligned}
& X=\text { the location of the camera } \\
& d=\text { the distance between } X \text { and } P \\
& P=\text { the projected point of the camera onto the }
\end{aligned}
$$

map

The distance, in parallel to the height of the buildings, raised problems as for the high definition of the video. The working group solved this problem by adding:

- The camera in the middle of the circular route of the race and
- After a number of tests, a limited range was chosen between the lower and upper viewing angle of the animation of the race.

Finally, the video analysis has the following characteristics relative to the quality of the project (Table 1).

Table 1: The characteristics of the animation

\begin{tabular}{c|c} 
Setting of video & Size \\
\hline Length & $00: 04: 12$ \\
Frame width & 1000 \\
Frame height & 562 \\
Data rate & $6421 \mathrm{kbps}$ \\
Total bitrate & $6738 \mathrm{kbps}$ \\
Frame rate & $29.97 \mathrm{FPS}$
\end{tabular}

\subsection{The analysis of methodology}

The three-dimensional video aims at the digital documentation and recording of the historical monuments and buildings in the area. It is a way of digital representation and storage of the sporting event and the cultural wealth of the traditional quarter of Thessaloniki (Fig. 3):

1) The design of the route with GRASS, is important for the race route delimitation. The construction of the route was under World Geodetic System (WGS84) in order to be compatible with Google Earth Studio. The race route was digitized on-screen with a distinct colour to stand out on the map.

2) The first step of the design process was to upload the race route into Google Earth Studio. The coordinate system must be the same to get a successful connection of the race route to the background of the map. The digitization of the route was done to limit the study area.

3) The next step was the installation of the camera station. It was crucial for the camera placement to be installed both in a conspicuous position from the points of interest and in the middle of the circular race route for two reasons:

- The final product should be attractive with the simplicity and clarity of information.

- The cultural points of interest should be wellpresented.

4) The design of the three-dimensional map was based on the successive overlaid photos. Both the overlay between two consecutive photos and the subsequent one must be large enough. This created a better synthesis between images for the next step of rendering. Also, the creation of images was done with small consecutive tracks of the camera, which were timed sequentially (Fig. 4). 


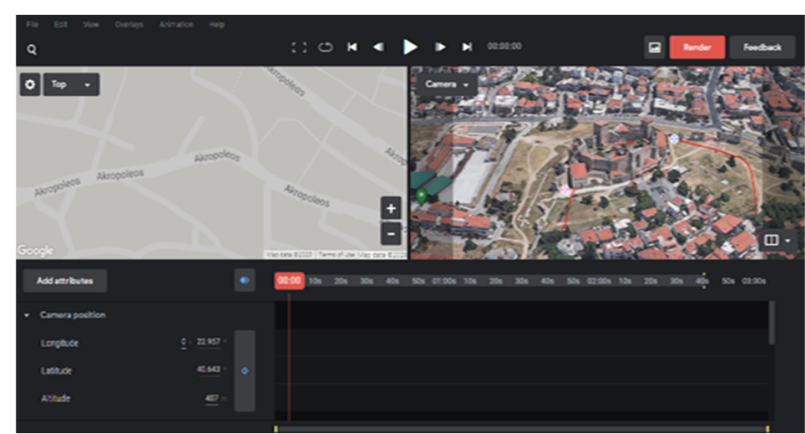

Figure 3: Transition from 2D to 3D (snapshot from the Google Earth Studio).

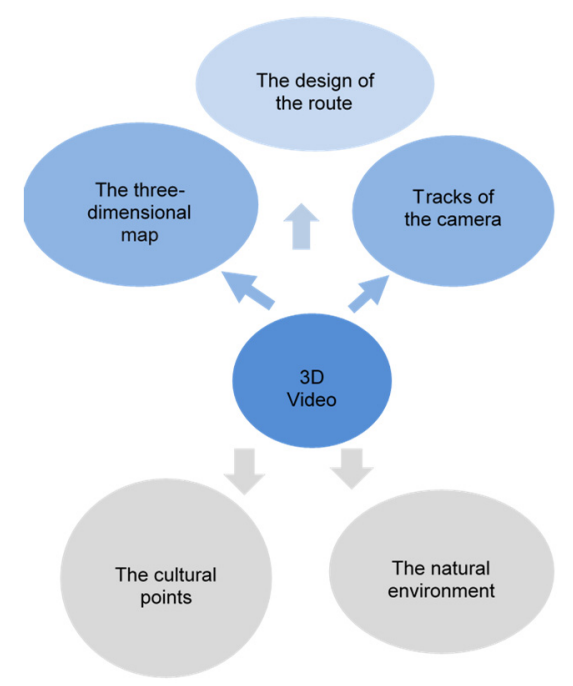

Figure 4: Technical sets for the 3D video and sites of interest.

One challenge faced by the working group was the clarity of all points. The main factor that contributed to the sharpness was the fixed camera located in the middle of the map of the study area. Besides that, the angle of shooting was slightly shifted, without changing the orientation of the map.

The route of the race was circular, resulting in the 60 degree angles, which was the biggest problem for the presentation of the area. Finally, putting labels on the historical sites was an important task for making the map more attractive.

\section{Results}

\subsection{Summary of the project}

The purpose of this paper is interdisciplinary. Initially, the work generates data, which are capable of recording cultural heritage. In addition, 3D video preserves the cultural value of the architectural landscape, monuments and natural environment in 3D geospatial representation (Landes, Grussenmeyer, Voegtle, \& Ringle, 2007).

The final video transforms the $2 \mathrm{D}$ track into $3 \mathrm{D}$ panoramic viewing. The advantages are the speed in the rotation of the video, the panoramic viewing of the area, the capture angles and the focus on points of cultural and architectural interest. (Emmanuel \& Grussenmeyer, 2012). Finally, the virtual tour was created during the pandemic without on-site recording.
The 3D mapping animation for the race purposes is innovative, because it is a multi-factor result of the following indexes:

1) Records part of the outdoor area.

2) Designs the route of the race.

3) Promotes the historic sites of Thessaloniki city.

4) Analyzes the historical background of the old - city.

5) The methodology uses a wide - range software with low - cost construction.

6) Human vision is made for a $3 D$ world and thus can easily deal with the relative position of natural and man-made characteristics when shown in an animation. Even more so when the animation is 3D.

The procedure started with the delimitation of the route of the race. For this purpose, we used GRASS GIS for the construction of a shapefile under WGS84 coordinate system. This system is the same that Google Earth Studio uses and helps the layer to overlay correctly on Google's imagery. Then, the transformation from $2 D$ images to $3 D$ with successive and overlapping snapshots was designed and the rendering process for the union of successive images resulted to the final product of a $3 D$ animated map.

\subsection{Photograph's Snapshots of the 3D Mapping}

The photos show snapshots from the video. They are from the beginning of the race (Fig. 5) and follow the route to the finish (Fig. 6), through the transition zone of Old and modern City (Fig. 7) and the border between the Old and modern City (Fig. 8). The route is of very significant cultural value, with monuments, landfills, administration buildings, green spaces (Fig. 9). The route bridges the history of three civilizations with modern elements for example urban regeneration, and hiking.

Finally, the athletes and the visitors of the race play in a creative way knowing the history, the culture of the area. The innovation of the Municipality of Thessaloniki promotes participation, fair play, and the noble rivalry between the athletes.

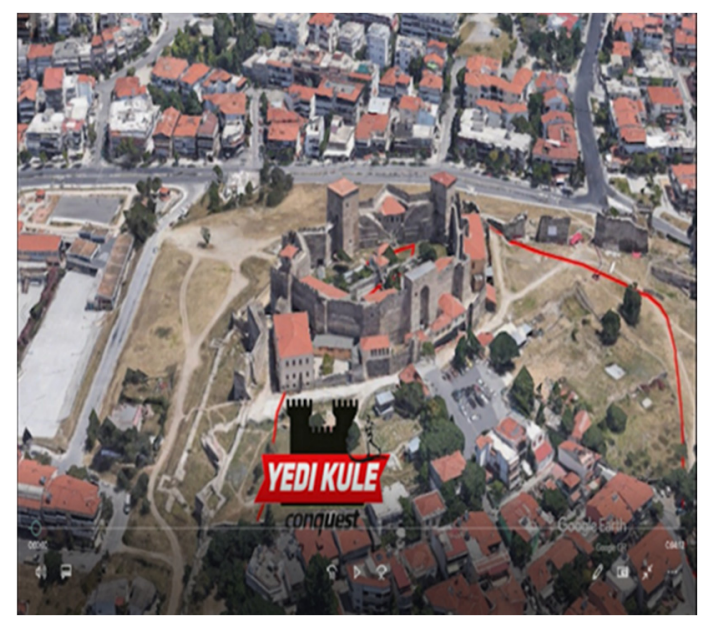

Figure 5: The beginning of 3D Mapping (snapshot from Google Earth Studio) 


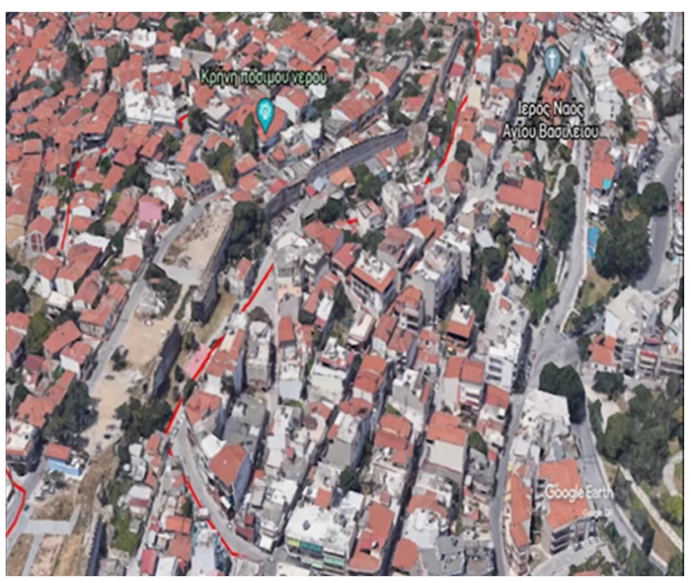

Figure 6: At the middle of the route (snapshot from Google Earth Studio).

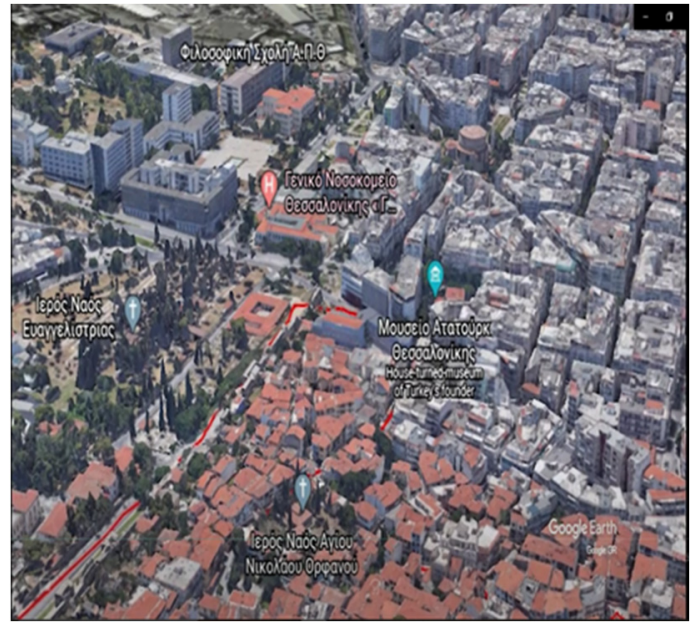

Figure 7: The lower location of the race (snapshot from Google Earth Studio).

\section{Conclusion}

Documentation is a specific component of the preservation chain since it contains all the details required to clarify the item in question and contributes to the implementation of the best safeguarding practices. Some form of protection of cultural heritage is assured through documentation. It also acts as an instrument for practitioners and experts, public bodies and the general public to interact and raise awareness (Stylianidis, 2019). The application of the Google Earth Studio covers the gap between the construction of the 3D Mapping in the online environment and the animation of the digital map. The result is based on the right use of the scientific methodology of the Google Earth Studio and also the scientific documentation about the history of the area and city history. This way, the 3D animation enhances the digital representation of the cultural route and all the monuments and important sites found on the race route.

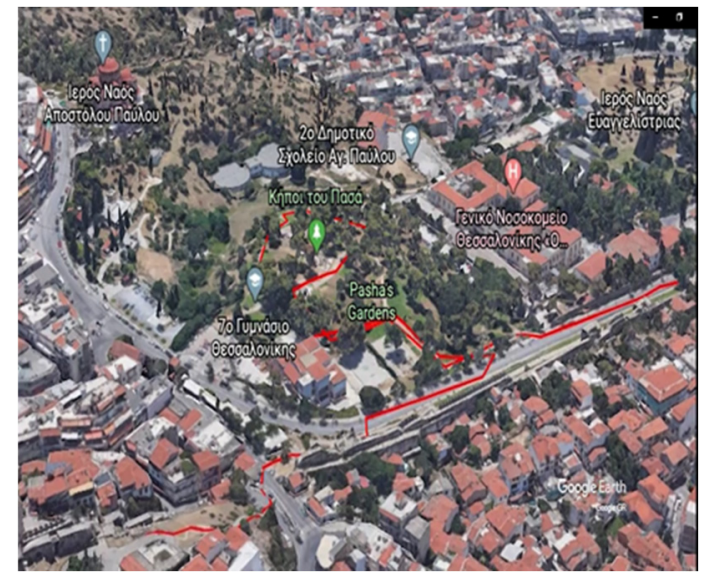

Figure 8: The castle and the green space (snapshot from Google Earth Studio).

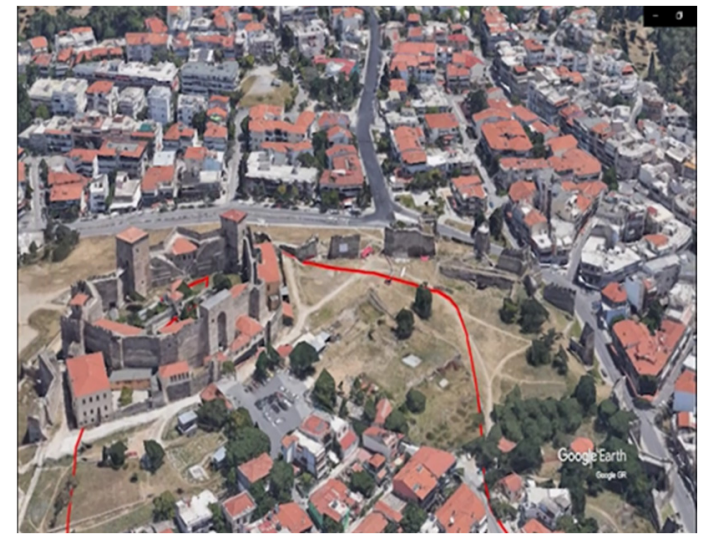

Figure 9: The end of the race (snapshot from Google Earth Studio).

\section{References}

Anastasiadis, G. (2011). Chronologio of Thessaloniki Part II. Thessaloniki on Polis, March 2011, p. 13.

Benbassa, E., Rodrigue, A., \& Jewry, S., (2000). A History of the Judeo-Spanish Community, $14^{\text {th }}-20^{\text {th }}$ Centuries. University of California Press, Los Angeles.

Balcells, L., \& Torrats-Espinosa, G. (2018). The electoral consequences of terrorism: Evidence from a natural experiment. Proceedings of the National Academy of Sciences 115(42), 10624-10629.

Bol, D., Giani, M., Blais, A., \& Loweven, J. P., (2020). The effect of COVID-19 lockdowns on political support: Some good news for democracy? European Journal of Political Research. https://doi.org/10.1111/1475-6765.12401

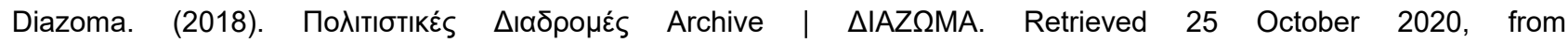
https://www.diazoma.gr/cultural-routes/

Emmanuel, A., \& Grussenmeyer, P. (2012). From point cloud to 3D model, modelling methods based on architectural knowledge applied to fortress of Chatel-sur-moselle (FRANCE). International Archives of the Photogrammetry, Remote Sensing and Spatial Information Sciences, XXXIX-B5. https://doi.org/10.5194/isprsarchives-XXXIX-B5-75- 
2012

Gerolympou-Karadimos, A. (1995). The reconstruction of Thessaloniki after the fire of 1917, Thessaloniki Ed. University Studio Press.

Giannakou, A. (2015). Land policy programs in Thessaloniki from the interwar to the 1960s: The transition to a modern metropolitan area. In: D. Kiridis (Ed.), Thessaloniki: a city in transition 1912-2012. Thessaloniki: Epicenter A.E, pp. 487-488.

Google Earth Studio. (2020). Introducción - Google Earth Studio. Retrieved 28 October 2020, from https://earth.google.com/studio/docs/

Gregoriou, A. X., \& Hekimoglou, E. (2008). Thessaloniki of travelers 1430-1930: choices of texts and testimonies. Athens. Miletus and Society of Macedonian studies.

Guo, J., Zhang, J. X., Zhao, H. T., Li, C., Zhou, J., Tu, H. J., \& Zhao, Y. (2020). Horizontal accuracy assessment of Google Earth data over typical regions of Asia. Int. Arch. Photogramm. Remote Sens. Spatial Inf. Sci., XLIII-B3-2020, 13331338. https://doi.org/10.5194/isprs-archives-XLIII-B3-2020-1333-2020

Harell, A. (2020). How Canada's pandemic is shifting political views. Report for the Institute for Research on Public Policy. Retrieved May, 19, 2020 from https://policyoptions.irpp.org/fr/magazines/avril-2020/how-canadaspandemicresponse-is-shifting-political-views/

Hastaoglou-Martinidis, V. (1997). A Mediterranean City in Transition: Thessaloniki between the Two World Wars. Facta Universitatis, Ser. Architecture and Civil Engineering., 1(4), 493-507.

Hetherington, M.J., \& Nelson, M. (2003). Anatomy of a rally effect: George W. Bush and the war on terrorism. PS: Tania

Landes, T., Grussenmeyer, P., Voegtle, T,. \& Ringle, K. (2007). Combination of Terrestrial Recording Techniques for 3D Object Modelling regarding topographic constraints. Example of the Castle of Haut-Andlau, Alsace, France.. XXIth CIPA International Symposium, Oct 2007, Athenes, Greece. pp.435-440. halshs-00264855 Political Science \& Politics, 36(1), 37-42.

Mazower, M. (2006). Thessaloniki, city of ghosts: Christians, Muslims and Jews, 1430-1950. 1st Ed. Athens. Alexandria.

Machaira, A. (2002). Thessaloniki of the interwar period. History of Greece of the $20^{\text {th }}$ century, 1922-1940. In: X. Hatziosif (Ed.), The Interwar. Athens. Bibliorama, pp.107-131.

Merkley, E., Bridgeman, A., Loewen, P.J., Owen, T., Ruths, D., \& Zhilin, O. (2020). A rare moment of cross-partisan consensus: Elite and public response to the COVID-19 pandemic in Canada. Canadian Journal of Political Science, First View.

Pierron. (2004). Jews and Christians of modern Greece. History of intercommunity relations from 1821 to 1945. Polis.

Strabon. (1992). Geographia 7. Kaktos Publ., Athens (in Greek).

Stylianidis, E. (2019). CIPA - Heritage Documentation: 50 Years: Looking Backwards, Int. Arch. Photogramm. Remote Sens. Spatial Inf. Sci., XLII-2/W14, 1-130. https://doi.org/10.5194/isprs-archives-XLII-2-W14-1-2019

Thessaloniki tourism Organization (2020). Thessaloniki Tourism - Heptapyrgion - Yedi Kule. Retrieved 30 September 2020 , from https://www.thessalonikitourism.gr/index.php/en/component/k2/item/107-heptapyrgion-yedi-kule

Unesco World Heritage Site. (2020). Paleochristian and Byzantine Monuments of Thessalonika - UNESCO World Heritage Centre. Retrieved 20 October 2020, from http://whc.unesco.org/en/list/456/

Vakalopoulos, A. (1983). History of Thessaloniki 316 P.X -1983. Thessaloniki. Altintzis Publications. 